\title{
Phenylpropanoid-substituted Procyanidins and Tentatively Identified Procyanidin Glycosides from Hawthorn (Crataegus spp.)
}

Authors

Affiliation
Jandirk Sendker, Frank Petereit, Marcus Lautenschläger, Nils Hellenbrand, Andreas Hensel

University of Münster, Institute of Pharmaceutical Biology and Phytochemistry, Münster, Deutschland
Key words

- Crataegus spp.

- Rosaceae

procyanidins

- cinchonain IIb

procyanidin glycosides received April 9, 2012

revised October 7, 2012

accepted October 18, 2012

Bibliography

Dol http://dx.doi.org/

10.1055/s-0032-1327926

Published online November 15 ,

2012

Planta Med 2013; 79: 45-51

(c) Georg Thieme Verlag KG

Stuttgart · New York .

ISSN 0032-0943

\section{Correspondence}

Prof. Dr. Andreas Hensel University of Münster

Institute of Pharmaceutical

Biology and Phytochemistry

Hittorfstr. 56

48149 Münster

Deutschland

Phone: + 492518333380

Fax: + 49251838341

ahensel@uni-muenster.de

\section{Abstract \\ $\nabla$}

The rational use of hawthorn leafs and flowers from Crataegus spp. for declining cardiac performance is mainly due to flavon-C-glycosides and oligomeric procyanidins (OPC). From OPC-enriched extracts from different batches, a dimeric phenylpropanoid-substituted procyanidin (cinchonain II b, 1) was isolated and characterized by MS, CD, and NMR. Also the presence of higher oligomeric cinchonains (degree of polymerization 3 to 8 ) in hawthorn extracts was shown by a specific ultrahigh-pressure liquid chromatography-ESIqTOF-MS method. Interestingly, strong evidence for the occurrence of oligomeric procyanidin hexosides was found by ultrahigh-pressure liquid chromatography-ESI-qTOF-MS analysis which

\section{Introduction}

$\nabla$

Hawthorn leaves and flowers consist of the dried flowering branches of Crataegus monogyna Jacq. (Lindm.), C. laevigata (Poiret) DC. (Rosaceae), and, more rarely, C. pentagyna Waldst. \& Kit. ex Willd., C. nigra Waldst. \& Kit., and C. azarolus L. Pharmaceutical preparations of hawthorn are considered as a rational based phytomedicine against declining cardiac performance corresponding to the functional classification class I and II, as defined by the New York Heart Association (NYHA) [1]. Also a recent meta-analysis indicates a significant benefit in symptom control and physiologic outcome from hawthorn extract as an adjunctive treatment of chronic heart failure [2]. The main constituents are flavonoids (up to $2 \%$ ), such as vitexin, vitexin-2"-rhamnoside, hyperoside, rutin, approximately $3 \%$ of oligo- and polymeric B-type procyanidins [3], triterpenes, phenolic acids, amines, xanthines, and polysaccharides [4]. From the functional point of view, flavone-C-glycosides and OPCs are considered to additionally revealed the presence of peaks indicative of dimeric procyanidin hexosides by their exact mass, which were clearly distinguishable from the cinchonain II type peaks.

\section{Abbreviations \\ $\nabla$ \\ DP: $\quad$ degree of polymerization \\ OPC: $\quad$ oligomeric procyanidin \\ UHPLC: ultrahigh-pressure liquid chromatography}

Supporting information available online at http://www.thieme-connect.de/ejournals/toc/ plantamedica

be the main active compounds (ESCOP 2003). For a recent summary of the phytochemistry and problems concerning the analysis of procyanidins from hawthorn, see [3] and references cited there. Despite the fact that OPCs are claimed to be part of the active ingredients, data published on the cardiac activity of hawthorn did not use pure OPCs but multicompound extracts, standardized on procyanidin content [5-7]. On the other side, the B-type OPCs from hawthorn are a complex heterologous series with DP 2 to 13 and a polymeric procyanidin fraction. Therefore, an efficient methodology for the purification of oligomeric procyanidins with defined DP has been established in order to obtain sufficient amounts of test compounds for detailed structure-activity studies [8]. During the large scale purification of defined OPCs, a further homologous series of oligomeric cinchonains has been identified from the OPC fraction, a substance class described in this report for the first time for hawthorn leaves and flowers. 


\section{Materials and Methods}

$\nabla$

\section{General analytical techniques}

NMR spectra of the peracetylated derivatives were recorded in $\mathrm{CDCl}_{3}(\delta 7.26$ and $77.00 \mathrm{ppm})$ on a Varian Unity plus 600 , a Varian INOVA 500 , or a Varian m400 spectrometer. CD spectra were measured with a Jasco J-815 CD spectrometer in MeOH. Optical rotations were measured with a Perkin-Elmer 341 digital polarimeter in $\mathrm{MeOH}$. Analytical TLC was carried out on silica gel plates ( $0.2 \mathrm{~mm}$; Merck) using ethyl acetate/water/formic acid $(90: 5: 5)$ as the eluent. Compounds were visualized as red colored spots by spraying with vanillin- $\mathrm{HCl}$ reagent. Peracetylation of compounds was performed in pyridine/acetic acid anhydride $(1: 1)$ at room temperature for $24 \mathrm{~h}$ in the dark [9]. Analytical HPLC equipment was supplied from Waters: controller 600 unit, PDA 996, scanning fluorescence detector 474, autosampler 717 plus, in-line degasser AF, Millenium32 software.

\section{Plant material}

Two batches of the herbal drug material Crataegi folium cum flore (batches no. 52467097 and 09363903), conforming to the specifications of Ph. Eur. 6, were obtained from Caesar \& Loretz. Reference samples (voucher samples IPBP-240 and 249) are stored at the Institute of Pharmaceutical Biology and Phytochemistry.

Additionally fresh plant material (leaves and flowers) from C. monogyna L. (identified by A.H.) was collected on May 28th 2011 at the Medicinal Plant Botanical Garden of the University of Münster, Germany. The material was dried at room temperature; a reference sample (voucher sample IPBP-251) is stored at the Institute of Pharmaceutical Biology and Phytochemistry.

\section{Preparation of fraction E4 and subfraction c}

\section{(see also Supporting Information, Fig. 1S)}

Isolation and characterization of OPC clusters was performed as previously described [8]. The herbal material from batch $52467097(5.15 \mathrm{~kg})$ was extracted with acetone/water $(7: 3 \mathrm{v} / \mathrm{v})$ and successively concentrated in vacuo, filtered to remove precipitated chlorophyll, further concentrated and defatted with petroleum benzine. Successive extraction of the aqueous phase with EtOAc yielded an EtOAc-fraction (126 g, corresponding to $2.6 \%$ ) and a water fraction ( $859 \mathrm{~g}$, corresponding to $16.7 \%$, related to the starting material). The EtOAc fraction was resuspended in ethanol and centrifuged. The resulting supernatant, corresponding to $85 \mathrm{~g}$ of dry mass, was subjected to Sephadex ${ }^{\circledR}$ LH-20 chromatography [ $675 \times 55 \mathrm{~mm}$, eluents: ethanol 96\% $13 \mathrm{~L}$, methanol $9 \mathrm{~L}$, acetone/water $(7: 3) 3.9 \mathrm{~L}$, flow $1.5-2 \mathrm{~mL} / \mathrm{min}$, fraction size $15 \mathrm{~mL}$. All fractions eluted were investigated by TLC, and fractions with comparable composition were combined. The subfraction E4 (elution from 5.8 to $8.4 \mathrm{~L}$, yield $1.83 \mathrm{~g}$ ) contained high amounts of a dimeric procyanidin cluster and was subjected to preparative HPLC for the isolation of cinchonains.

The dried water fraction was divided into a $\mathrm{MeOH}$-soluble extract and a $\mathrm{MeOH}$-insoluble residue. An aliquot of the $\mathrm{MeOH}-$ soluble extract $(1.30 \mathrm{~g})$ was further fractionated by MPLC [RP18, 18-32 $\mu \mathrm{m}, 100 \AA$, $36 \times 500 \mathrm{~mm}$, Best Technik, flow $8 \mathrm{~mL} / \mathrm{min}$, step gradient $\mathrm{MeOH}$ 10\% (25 min) $\rightarrow \mathrm{MeOH} \mathrm{30 \%} \mathrm{(1} \mathrm{h)} \rightarrow$ MeOH 50\% $(1 \mathrm{~h}) \rightarrow \mathrm{MeOH}(1 \mathrm{~h})]$ to yield the procyanidin-containing subfraction c (elution from 0.75 to $1.25 \mathrm{~L}$ ) (0.16 g). Subfraction c was further subjected to preparative HPLC on a diol stationary phase (Uptisphere ${ }^{\circledR} 120 \AA$, bonding $\mathrm{OH}, 6 \mu \mathrm{m}, 21.2 \times 250 \mathrm{~mm}$; Interchim) using a binary gradient of acetonitrile (A) and methanol/ water $(95: 5)$ (B) for the isolation of procyanidin clusters DP3 to
13. Gradient: 0 min: A $100 \% \rightarrow 30$ min: A $60 \% \rightarrow 40$ min: A $60 \%$ $\rightarrow 45 \mathrm{~min} \mathrm{~A} 65 \% \rightarrow 50 \mathrm{~min}:$ A $0 \% \rightarrow 55 \mathrm{~min}:$ A $0 \% \rightarrow 60 \mathrm{~min}: A$ $100 \%$; flow rate $10 \mathrm{~mL} / \mathrm{min}$.

\section{Isolation of cinchonain II b}

Isolation of cinchonains was performed from subfraction E4 by preparative HPLC on a diol stationary phase (Uptisphere ${ }^{\circledR} 120 \AA$, bonding $\mathrm{OH}, 6 \mu \mathrm{m}, 21.2 \times 250 \mathrm{~mm}$; Interchim) using a binary gradient with acetonitrile (A) and $\mathrm{MeOH} /$ water (95:5) (B) $\left(t_{0 \mathrm{~min}}\right.$ $100 \% \mathrm{~A}, t_{35 \min } 70 \% \mathrm{~A}, t_{39 \min } 100 \% \mathrm{~B}, t_{44 \min } 100 \% \mathrm{~B} 5 \mathrm{~min}$ isocratic). Besides a major peak of dimeric OPCs, an unknown compound eluting at $t_{\mathrm{R}}=26.7 \mathrm{~min}$ was collected to yield fraction E4-3 (13.9 mg from $302 \mathrm{mg}$ of fraction E4) (Fig. 2S, Supporting Information). By UHPLC-ESI-TOF-MS analysis, this fraction was shown to contain a substance with the monoisotopic mass of a dimeric cinchonain $\left(m / z 739,[\mathrm{M}-\mathrm{H}]^{-}\right)$, but still was contaminated with substantial amounts of a dimeric OPC $\left(m / z 577[\mathrm{M}-\mathrm{H}]^{-}\right)$(Fig. 4S, Supporting Information).

Further preparative purification of this fraction (13 mg) was performed on a RP18 stationary phase (Hypersil ${ }^{\circledR}$ ODS, $5 \mu \mathrm{m}$, $250 \times 16 \mathrm{~mm}$ ), eluted with a binary gradient of $\mathrm{MeOH}(\mathrm{A})$ and $0.1 \%$ TFA (B), $t_{0 \text { min }} 5 \% \mathrm{~A}, t_{15 \min } 30 \% \mathrm{~A}, t_{25 \text { min }} 40 \% \mathrm{~A}, t_{30 \text { min }} 100 \%$ A; flow $10 \mathrm{~mL} / \mathrm{min}$ (Fig. 3S, Supporting Information). Five peaks were obtained under these conditions from E4-3, of which the third eluting peak at $t_{\mathrm{R}}=19.3 \mathrm{~min}$ was isolated (E4-3/3, yield $6.5 \mathrm{mg}$ ) and identified by MS/MS (positive mode) as a dimeric cinchonain $\left(m / z 741[\mathrm{M}+\mathrm{H}]^{+}\right)$.

\section{ESI-q-TOF analysis of subfraction $c$ and fragmentation analysis of cinchonain II b (m/z 739)}

A solution of $0.1 \mathrm{mg} / \mathrm{mL}$ subfraction c in isopropanol $50 \%$ was directly infused into an Apollo ESI source of a Bruker Daltonics micrOTOF QII (Bruker Daltonics). Direct infusion was rationalized for getting higher signal intensity for fragmentation analysis. Settings: flow rate $3 \mu \mathrm{L} / \mathrm{min}$ in the negative mode; mass range $\mathrm{m} / \mathrm{z}$ 50-1000; nebulizer gas nitrogen, 0.4 bar; dry gas nitrogen, $4.0 \mathrm{~L} /$ min, $180^{\circ} \mathrm{C}$; capillary voltage $4500 \mathrm{eV}$; end plate offset $-500 \mathrm{eV}$; transfer time $100 \mu \mathrm{s}$; prepulse storage $5.0 \mu \mathrm{s}$; ion energy $-3 \mathrm{eV}$; low mass $m / z$ 320. Collision cell RF settings were combined to each single spectrum of 5000 summations as follows: 2500 summations with $300 \mathrm{Vpp}+2500$ summations with $130 \mathrm{Vpp}$. Collision energy for $m / z 739$ was varied between $-5 \mathrm{eV}$ and $-80 \mathrm{eV}$ in order to detect a wide range of fragments. Instrument calibration and internal data set calibration was performed using a $10 \mathrm{mM}$ sodium formiat solution in $50 \%$ isopropanol that was directly infused into the ESI source by a syringe pump at $3 \mu \mathrm{L} / \mathrm{min}$.

\section{UHPLC-ESI-qTOF-MS of procyanidin clusters and cinchonains}

Test solutions: $0.1 \mathrm{mg} / \mathrm{mL}$ subfraction c, prepared from batch 52467097 , was dissolved in isopropanol 50\%. Preparation of test solutions from batch 09363903 and from C. monogyna leaves and flowers was performed as follows: $3 \mathrm{~g}$ of herbal drug was pulverized in liquid nitrogen and sieved over a $0.800-\mathrm{mm}$ sieve (DIN 4188). $0.50 \mathrm{~g}$ of the pulverized material was extracted with $10 \mathrm{~mL}$ of acetone: water $(7: 3 \mathrm{v} / \mathrm{v})$ by a rotor-stator system (Ultra-Turrax; ICA) for $6 \times 1 \mathrm{~min}$; the suspension was filtered over a glass filter (Duran ${ }^{\circledR}$; Schott). The organic part of the solvent from the combined extracts was removed using a rotary evaporator, and the resulting aqueous suspension transferred to a $20.0-\mathrm{mL}$ flask, which was filled up with water. 


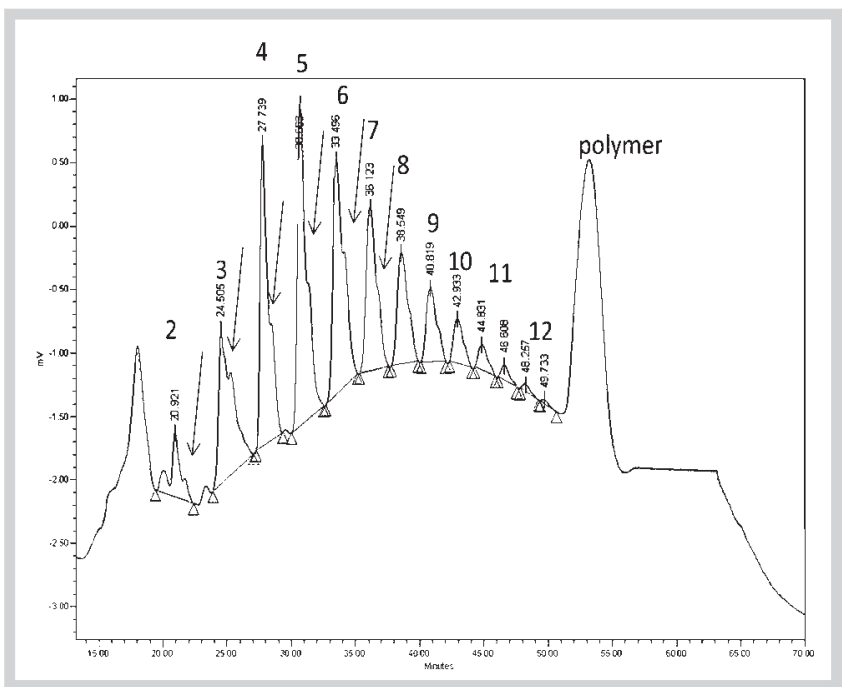

Fig. 1 Representative HPLC chromatogram of OPC-enriched subfraction c, containing clusters of DP 2 to DP 12 and polymeric procyanidins; arrows indicate oligomeric cinchonains at the peak tails of procyanidin peaks, numbers give degree of polymerization (DP). Gradient: acetonitrile (A), $\mathrm{MeOH}$ : water $(95: 5)$ (B) gradient $\left(t_{0 \text { min }} 100 \% \mathrm{~A}, t_{20 \text { min. }} 70 \% \mathrm{~A}, t_{45 \text { min }} 50 \%\right.$ A, $t_{50 \text { min }} 100 \%$ B 5 min. isocratic).

Chromatographic separation was performed on a Dionex 3000 RS liquid chromatography system (Thermo Fisher Scientific, Inc.) on an Uptisphere $120 \AA$, bonding $\mathrm{OH}, 6 \mu \mathrm{m}, 250 \times 4.6 \mathrm{~mm}$ column (Interchim) with a binary gradient modified according to [10] [A: acetonitrile/acetic acid (98:2), B: methanol/water/acetic acid (95:3:2)] at $40{ }^{\circ} \mathrm{C}$ and $0.8 \mathrm{~mL} / \mathrm{min}: 0-38 \mathrm{~min} 100 \% \mathrm{~A} \rightarrow 60 \% \mathrm{~A}$, $38-45$ min $60 \%$ A, $45-50$ min $60 \%$ A $\rightarrow 0 \%$ A, 50-60 min $0 \%$ A, 60-65 min. Reequilibration time: $5 \mathrm{~min}$. The injection volume was $10 \mu \mathrm{L}$. Eluted compounds were detected using a Bruker Daltonics micrOTOF-QII time-of-flight mass spectrometer equipped with an Apollo electrospray ionization source in the negative mode at $2 \mathrm{~Hz}$ over a mass range of $m / z 50-3000$ using the following settings: nebulizer gas nitrogen, 5 bar; dry gas nitrogen, $9 \mathrm{~L} /$ $\min , 180^{\circ} \mathrm{C}$; capillary voltage $2600 \mathrm{~V}$; end plate offset $-500 \mathrm{~V}$; transfer time $140 \mu \mathrm{s}$; prepulse storage time $15 \mu \mathrm{s}$; ion energy $-5.0 \mathrm{eV}$; low mass $\mathrm{m} / \mathrm{z} 300$. Collision cell RF settings were combined to each single spectrum of 2500 summations as follows: 1250 summations with $300 \mathrm{Vpp}+1250$ summations with 600 Vpp. Internal data set calibration (HPC mode) was performed for each analysis using the mass spectrum of a 10-mM sodium acetate solution in 50\% isopropanol that was infused during LC reequilibration using a divert valve equipped with a $20-\mu \mathrm{L}$ sample loop.

\section{Supporting information}

The extraction scheme of hawthorn leaves and flowers, the fragment list of cinchonain IIb, HPLC chromatograms of fraction E4 and E4-3, and spectra for cinchonain II b are available as Supporting Information.

\section{Results and Discussion}

$\nabla$

Recently, an HPLC method on the diol stationary phase for the effective preparative isolation of oligomeric procyanidin clusters (mixtures of procyanidins with identical molecular weight but

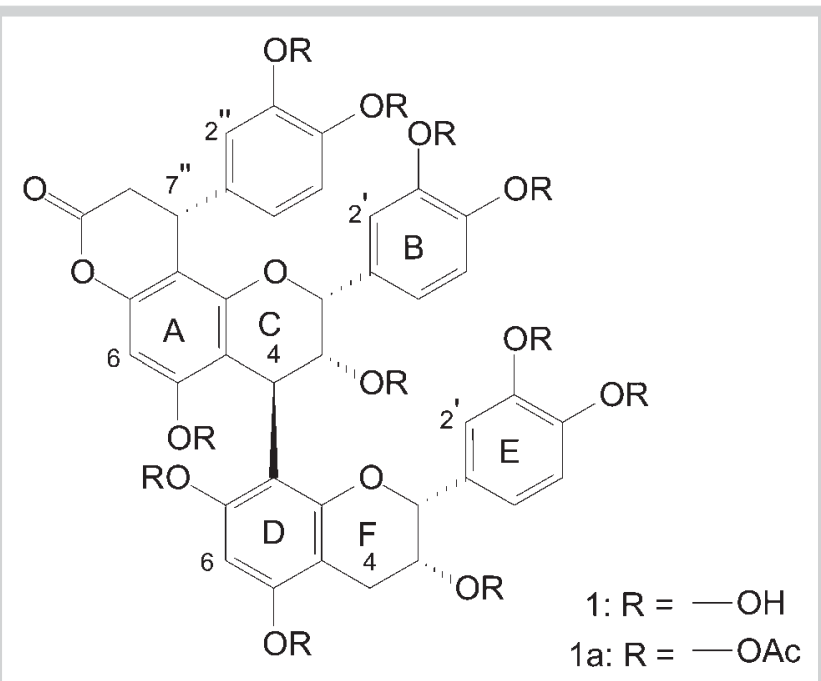

Fig. 2 Structure of cinchonain II b (1) isolated from hawthorn leaves and flowers and the respective cinchonain II b peracetate (1a) used for structure elucidation.

different stereochemistry and linkage types) with defined DP from hawthorn leafs and flowers has been described [8]. During the large scale OPC isolation from the procyanidin-enriched subfraction E4 (see Materials and Methods section), procyanidin clusters with DP 3 to 13 were isolated in good yields as distinct peaks (see Fig. 1 in [8]), but additionally it was observed that in cases where the preparative system was overloaded with high substance amounts, minor peaks were detected typically in the peak tails of procyanidins or in some cases within the valleys between the main peaks ( $\mathbf{F i g} \mathbf{1}$ ). For structure elucidation of compounds from these peaks, the following experiments were performed on a Sephadex LH20 fraction (E4) from the ethylacetate partition of an acetone/water extract (extraction scheme, see Fig. 1S, Supporting Information), focusing on the unknown compound eluting directly after the dimeric procyanidin cluster DP 2: by preparative HPLC on the diol stationary phase, this peak was isolated as fraction E4-3. By rechromatography of E4-3 on RP18, a pure fraction E4-3/3 (yield $6.5 \mathrm{mg}$ ) was isolated and characterized as a phenylpropanoid-substituted procyanidin from the cinchonain-type $\mathbf{1}$ ( Fig. 2).

The structure of 1, including the stereochemistry, was elucidated on the basis of its HR-MS data ( Fig. 3; Table 1S, Supporting Information, additionally lists typical MS fragments of cinchonain IIb after CID) and spectroscopic data (NMR, CD; for respective spectra, see Supporting Information Figs. 5S and 6S) of its peracetate $1 \mathbf{a}$ in comparison to recently published data [11]. The use of cinchonain peracetates is rationalized by an improved interpretation of NMR spectra by suppression of rotamer formation $(9,29$, 30). All measurements were in perfect congruence with the respective published data sets (10).

The identification of naturally occurring flavan-3-ols with a phenylpropanoid substitution of the cinchonain-type started 30 years ago by Nonaka and Nishioka and their coworkers [12-14]. The structures at that time were determined on the basis of spectroscopy followed by controlled degradation with identification of the resulting compounds. Comparison of the CD spectra of similar cinchonain analogues later has led to revision of the stereochemistry of cinchonains Ia-Id, IIa, and IIb as well as for the 


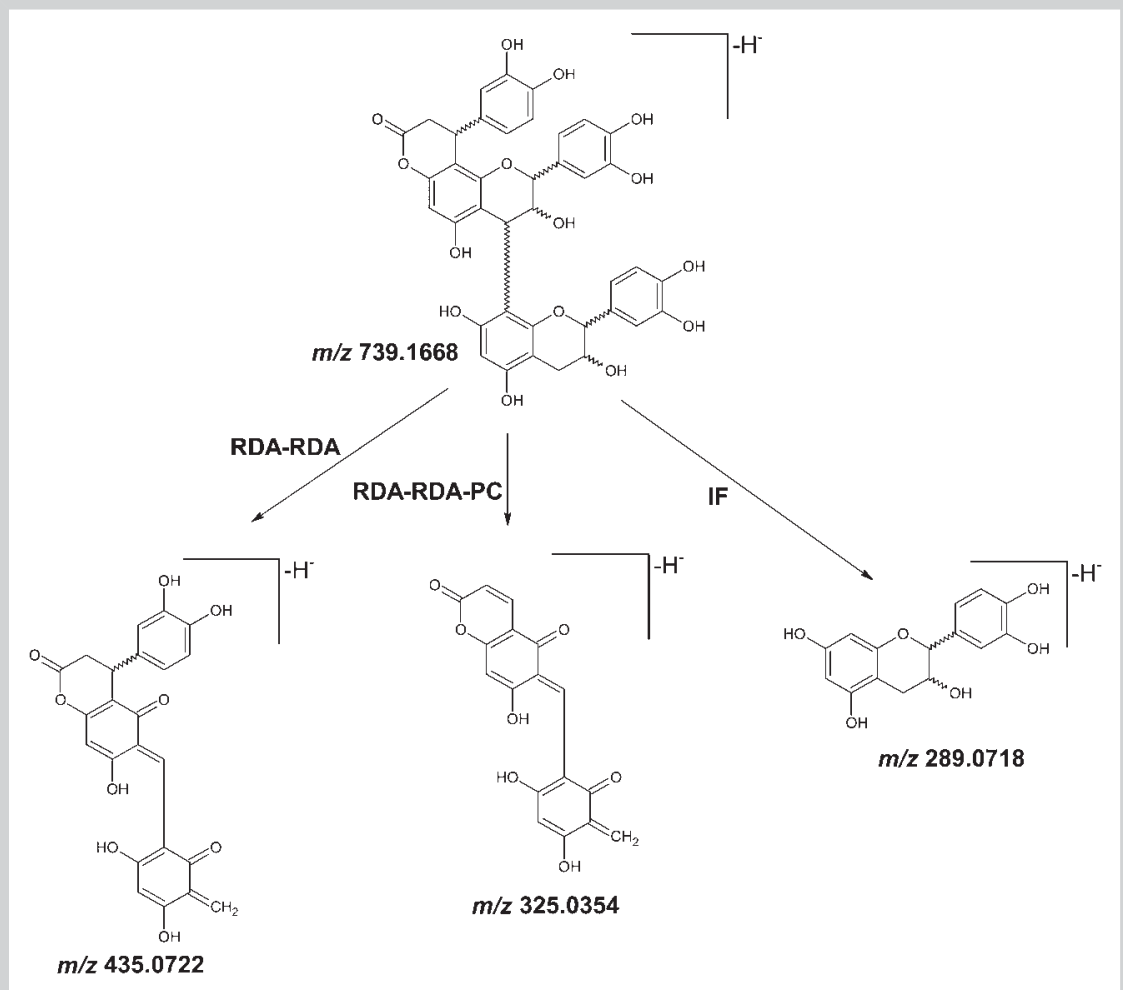

Fig. 3 Diagnostically important fragments of cinchonain dimer and their theoretical $\mathrm{m} / \mathrm{z}$ values. The fragments are indicative for the linkage of the $C_{9}$ moiety to the upper flavanol unit $(\mathrm{m} / \mathrm{z} 289)$ and to an A-Ring ( $\mathrm{m} / \mathrm{z} 435)$ as well as the presence of a dihydroxylated phenyl substructure within the $\mathrm{C}_{9}$ moiety ( $m / z$ 325) (RDA: retro-Diels-Alder reaction, PC: phenyl cleavage, IF: interflavan fission).

kandelins A1, A2 and B1, B2 [15]. The current generally accepted structure of cinchonain II b is shown in $\bullet$ Fig. 2. Our present study is the first report on cinchonains for the genus Crataegus. The occurrence of cinchonain-type flavan-3-ols within the Rosaceae family is strictly limited and, to our knowledge, until now only described for the genera Rhaphiolepsis [16] and Eriobotrya [1719].

Based on our findings of the dimeric phenylpropanoid-substituted procyanidin, further investigations were performed to elucidate if, additionally, a homologous series of cinchonains is detectable in the herbal material. For that, the procyanidin-enriched subfraction c (see extraction scheme, Fig. 1S, Supporting Information) was investigated by ESI-qTOF-MS. A series of weak MS-signals (series A) were detected that showed an offset of $162 \mathrm{u}$ relative to the more prominent series of dimeric $(M=578 \mathrm{u})$ to hexameric $(M=1730 \mathrm{u})$ procyanidins (series $\mathrm{B})$. Double charged members $[\mathrm{M}-2 \mathrm{H}]^{2-}$ of both series became increasingly dominant as their molecular weight exceeded $1000 \mathrm{u}$ and were used for the identification of larger molecules. The exact $m / z$ values for series $A$ are indicative for di- to hexameric procyanidins conjugated to a $\mathrm{C}_{9} \mathrm{H}_{6} \mathrm{O}_{3}$ moiety, as typically described for cinchonains [13]. The MS/MS signals of the most abundant ion $m / z 739$ from series A match the data published for cinchonain II isomers [20] and can predominantly be attributed to the fragmentation reactions of interflavan fission (IF), phenyl cleavage (PC), heteronuclear ring fission (HRF), and retro-Diels-Alder reaction (RDA) also known from proanthocyanidins [21,22]. Fragments of specific diagnostic value are (i) $\mathrm{m} / \mathrm{z} 435$ which results from repeated RDA and indicates linkage of the $C_{9}$ moiety to the A-ring of one flavanol subunit, (ii) $m / z 289$ which results from IF when the $C_{9}$ moiety is linked to the upper flavanol subunit (the complementary fragment $\mathrm{m} / \mathrm{z} 449$ could also result from repeated HRF when the $\mathrm{C}_{9}$ moiety is linked to the lower flavanol unit), and (iii) $m / z 325$ which can be explained by PC of $m / z$
435 , the neutral loss of $110 \mathrm{u}$ being indicative of the presence of a dihydroxylated phenyl ring within the $C_{9}$ moiety ( $\odot$ Fig. 3). Further fragmentation data and an MS/MS spectrum are given in Supporting Information, Table 15 and Fig. 4S, respectively. Based on the detection behavior of directly infused cinchonains, an UHPLC ESI-qTOF-MS analysis with optimized MS settings on a diol-modified silica column allowed the chromatographic separation and detection of the members of both series A (oligomeric cinchonains) from the monomer up to heptamers (० Fig. 4A) and series $\mathrm{B}$ (oligomeric procyanidins) by narrow base peak chromatograms (॰ Fig. 4B).

Detection of a homologous series of cinchonains was reproduced by investigation of two other samples, one being a commercial herbal drug of Crataegus leaves and flowers, meeting the specifications of European Pharmacopoeia. Further on, a collection of leaves and flowers from $C$. monogyna was investigated. Therefore, extracts prepared by acetone: water $(7: 3)$ were tested by ESIqTOF-MS, which revealed unambiguously the existence of cinchonains DP 2 to 7.

However, procyanidin hexosides show the same nominal but not exact masses and apparently - as demonstrated for the dimeric procyanidin hexoside - a similar fragmentation pattern which is comparable to the members of series A described here in our investigations [23]. Hence, high mass accuracy is required to distinguish them from the nominally isobaric cinchonains. The mass spectrometry instrumentation used in the present study allows the unambiguous discrimination of nominally isobaric cinchonains and procyanidin hexosides up to the level of hexamers $(M=1892 \mathrm{u})$. For detailed comparison of the measured $\mathrm{m} / \mathrm{z}$ signals with the theoretical data of cinchonains and procyanidin hexosides, see $\bigcirc$ Table 1 . This investigation and exact differentiation seems necessary because procyanidin hexosides have also been tentatively reported to occur in the genus Crataegus based on LC-MS analysis with low mass accuracy [24-26]; as no further 
Table 1 Comparison of the measured $\mathrm{m} / \mathrm{z}$ signals with the theoretical data of cinchonains and the nominally isobaric procyanidin hexosides. The instrument's mass accuracy of \pm 5 ppm allows a clear discrimination up to DP 6 [DP degree of polymerization, refers to the number of (epi)catechin building blocks].

\begin{tabular}{|c|c|c|c|c|c|c|c|}
\hline \multirow[t]{2}{*}{ DP } & \multicolumn{3}{|c|}{ Theoretical data of cinchonains } & \multirow{2}{*}{$\begin{array}{l}\text { Measured } \\
\mathrm{m} / \mathrm{z}\end{array}$} & \multicolumn{3}{|c|}{ Theoretical data of procyanidin hexosides } \\
\hline & Mol. form. & Theor. $m / z$ & Err [ppm] & & Err [ppm] & Theor. $m / z$ & Mol. form. \\
\hline 2 & $\mathrm{C}_{39} \mathrm{H}_{31} \mathrm{O}_{15}[\mathrm{M}-\mathrm{H}]^{-}$ & 739.1668 & 4.2 & 739.1699 & -24.5 & 739.1880 & $\mathrm{C}_{36} \mathrm{H}_{35} \mathrm{O}_{17}[\mathrm{M}-\mathrm{H}]^{-}$ \\
\hline 3 & $\mathrm{C}_{54} \mathrm{H}_{43} \mathrm{O}_{21}[\mathrm{M}-\mathrm{H}]^{-}$ & 1027.2302 & 0.8 & 1027.2310 & -19.9 & 1027.2514 & $\mathrm{C}_{51} \mathrm{H}_{47} \mathrm{O}_{23}[\mathrm{M}-\mathrm{H}]^{-}$ \\
\hline 4 & $\mathrm{C}_{69} \mathrm{H}_{55} \mathrm{O}_{27}[\mathrm{M}-\mathrm{H}]^{-}$ & 1315.2936 & 0.1 & 1315.2937 & -16.0 & 1315.3148 & $\mathrm{C}_{66} \mathrm{H}_{59} \mathrm{O}_{29}[\mathrm{M}-\mathrm{H}]^{-}$ \\
\hline 5 & $\mathrm{C}_{84} \mathrm{H}_{67} \mathrm{O}_{33}[\mathrm{M}-\mathrm{H}]^{-}$ & 1603.3570 & 3.0 & 1603.3618 & -10.2 & 1603.3782 & $\mathrm{C}_{81} \mathrm{H}_{71} \mathrm{O}_{35}[\mathrm{M}-\mathrm{H}]^{-}$ \\
\hline 6 & $\mathrm{C}_{99} \mathrm{H}_{78} \mathrm{O}_{39}[\mathrm{M}-2 \mathrm{H}]^{2-}$ & 945.2066 & 0.5 & 945.2070 & -10.5 & 945.2169 & $\mathrm{C}_{96} \mathrm{H}_{82} \mathrm{O}_{41}[\mathrm{M}-2 \mathrm{H}]^{2-}$ \\
\hline 7 & $\mathrm{C}_{114} \mathrm{H}_{90} \mathrm{O}_{45}[\mathrm{M}-2 \mathrm{H}]^{2-}$ & 1089.2383 & -3.2 & 1089.2348 & -12.7 & 1089.2348 & $\mathrm{C}_{111} \mathrm{H}_{94} \mathrm{O}_{47}[\mathrm{M}-2 \mathrm{H}]^{2-}$ \\
\hline
\end{tabular}

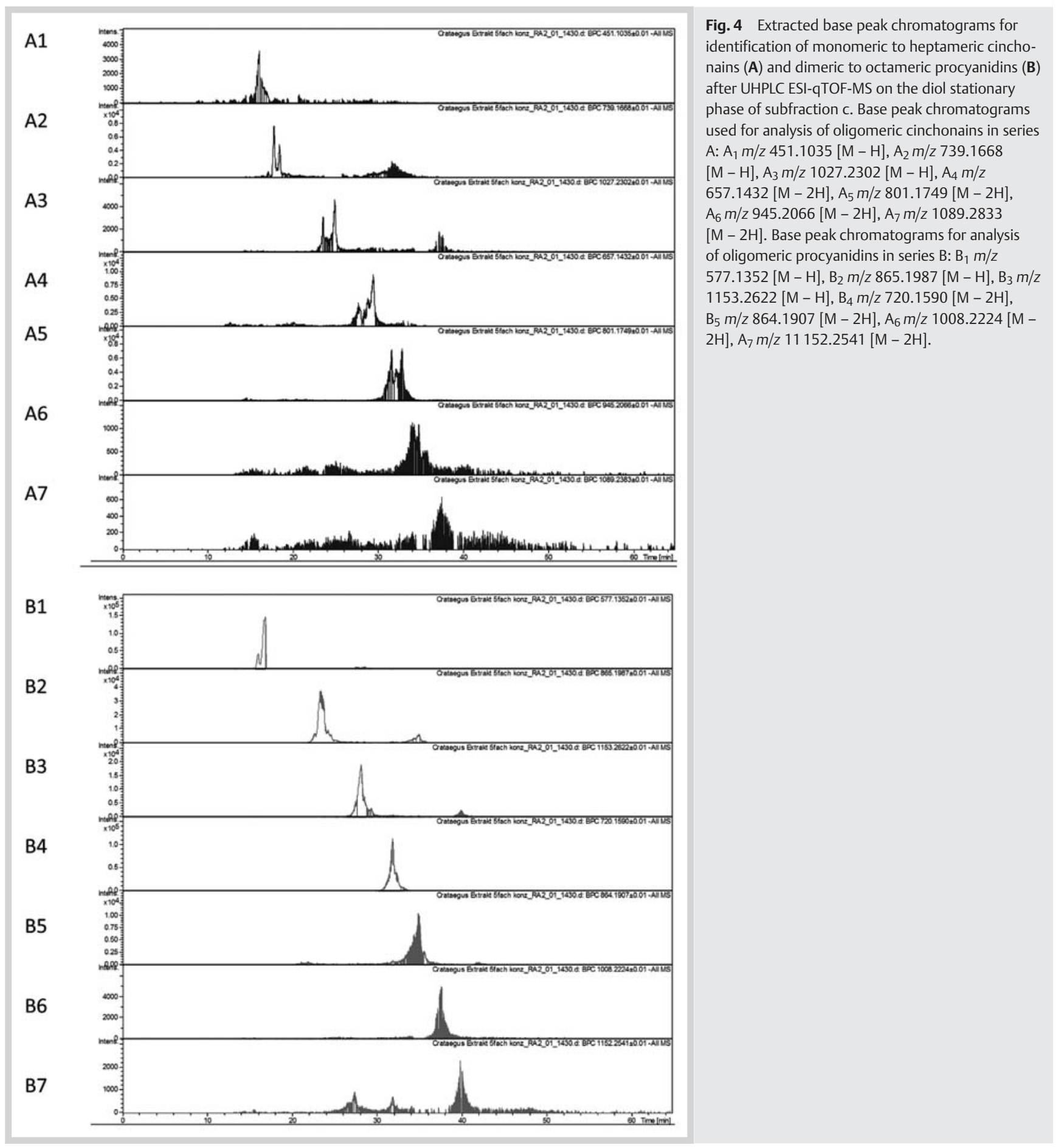




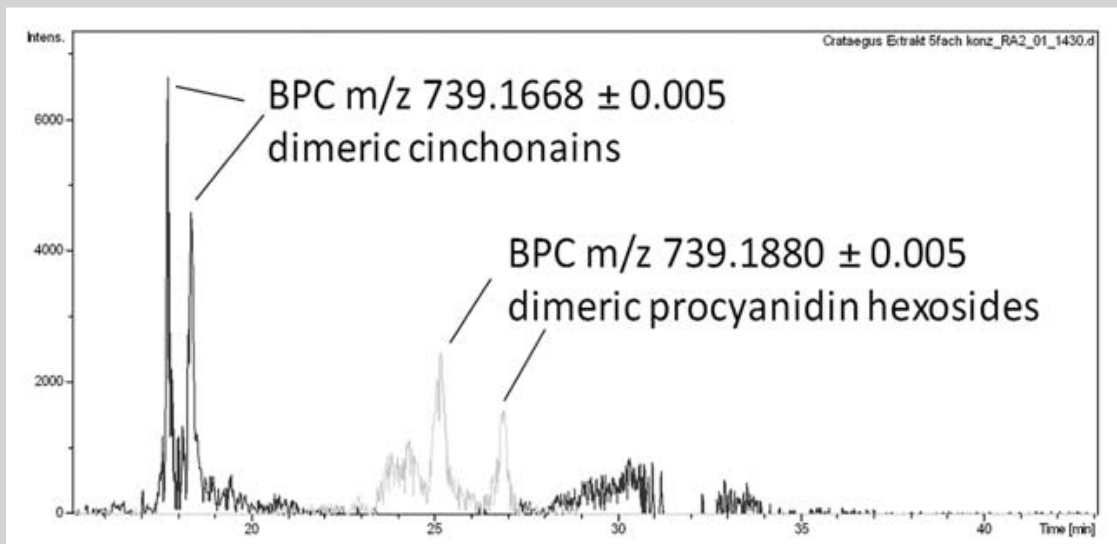

Fig. 5 Overlay of base peak chromatograms from hawthorn extract (subfraction c) for dimeric cinchonains and dimeric procyanidin hexosides. supportive data were presented in these studies, we suggest that the respective analytical signals might in part be attributed to the nominally isobaric cinchonains. The presence of procyanidin glycosides in the Rosaceae family has been convincingly demonstrated by Porter et al., who observed indicative chemical shifts in a ${ }^{13} \mathrm{C}-\mathrm{NMR}$ study of procyanidins isolated from Cydonia oblonga which yielded glucose upon acid hydrolysis [27].

The evaluation of UHPLC-ESI-qTOF-MS chromatograms and spectra obtained in our studies with OPC-enriched subfraction c, also containing the homologous series of cinchonains, additionally revealed the presence of a pair of peaks indicative for dimeric procyanidin hexosides by their exact mass ( $m / z$ 739.1880). These peaks were clearly separated from the two cinchonain II-type peaks ( $m / z$ 739.1668) ( Fig. 5). Unfortunately, a further MS/MS fragmentation of these peaks for detailed structural analysis was not possible due to low peak intensity. From these data, we can additionally assume the presence of a dimeric procyanidin glycoside with one hexose as a sugar moiety. Because two peaks are identified with the same mass, the existence of isomer pairs of the cinchonains and the tentative procyanidin hexosides can be expected. O-Glycosylation of the procyanidin backbone can be hypothesized to occur mainly at the hydroxyl groups at positions $7,3,5,3^{\prime}$, or $4^{\prime}$ as shown for synthetic catechin glucosides [28]. It seems interesting that certain flavan-3-ol glycosides show different intestinal stability and absorption characteristics compared to the unglycosylated compounds: e.g., catechin-3'-0-glucoside and catechin-7-O-glucoside are apparently better absorbed in an intestinal rat perfusion assay [28]. From these findings, further studies on pharmacokinetic and pharmacodynamic properties of oligomeric procyanidin glycosides and also for the group of cinchonains may be worth to be performed.

\section{Acknowledgements \\ $\nabla$}

We acknowledge Dr. Stefanie Zumdick for providing one procyanidin-enriched hawthorn extract and several fractions and Dr. Klaus Bergander, University of Münster, for recording the NMRspectra.

\section{Conflict of Interest}

$\nabla$

The authors state that they have no conflict of interest.

\section{References}

1 Crataegi folium cum flore (Hawthorn leaf and flower). In: European Scientific Cooperation on Phytotherapy. ESCOP Monographs, 2nd edition. Stuttgart: Thieme; 2003: 98-106

2 Guo R, Pittler MH, Ernst E. Hawthorn extract for treating chronic heart failure. Cochrane Database Syst Rev 2008; 1: CD005312

3 Petereit F, Nahrstedt A. Crataegus aus analytischer Sicht - Inhaltsstoffe offizineller Weißdorn-Drogen. Pharmazie in unserer Zeit 2005; 1: 22 26

4 Hensel A. Studies on polysaccharides and their extractability from $\mathrm{Cra}$ taegi folium cum flore. Pharmazie 1998; 53: 572-577

5 Leukel-Lenz A. Untersuchungen zur pharmakologischen Wirkung von Crataegus fraktionen und deren analytische Charakterisierung [dissertation]. Marburg: University of Marburg; 1988

6 Koch E, Chatterjee SS. Crataegus extract WS-1442 enhances coronary flow in the isolated rat heart by endothelial release of nitric oxide. Naunyn-Schmiedebergs Arch Pharmacol 2000; 361 (Suppl.): Abstract 180

7 Schmidt-Schweda S, v Bustin J, Möllmann H, Wollner S, Holubarsch C. Der positive inotrope Effekt des Crataegus-Spezialextraktes WS1442 in isolierten Myozyten aus menschlichem Vorhof- und Ventrikelmyokard wird vorwiegend durch oligomere Procyanidine vermittelt. Z Kardiol 2000; 89 (Suppl. 5): 164 (abstract 797)

8 Zumdick S, Petereit F, Luftmann H, Hensel A. Preparative isolation of oligomeric procyanidins from Hawthorn (Crataegus spp.). Pharmazie 2009; 64: 286-288

9 Bicker J, Petereit, A, Hensel A. Proanthocyanidins and a phloroglucinol derivative from Rumex acetosa L. Fitoterapia 2009; 80: 483-495

10 Kelm MA, Johnson JC, Robbins RJ, Hammerstone JF, Schmitz HH. High performance liquid separation and purification of cacao (Theobroma cacao L.) procyanidins according degree of polymerization using a diol stationary phase. J Agric Food Chem 2006; 54: 1571-1576

11 Resende FO, Rodrigues-Filho E, Luftmann H, Petereit F, Palazzo de Mello JC. Phenylpropanoid substituted flavan-3-ols from Trichilia catigua and their in vitro antioxidative activity. Braz Chem Soc 2011; 22: 2087-2093

12 Nonaka GI, Nishioka I. Tannins and related compounds. VII. Phenylpropanoid-substituted epicatechin, cinchonains from Cinchona succirubra. Chem Pharm Bull 1982; 30: 4268-4276

13 Nonaka GI, Kawahara O, Nishioka I. Tannins and related compounds. VIII. A new type of proanthocyanidin, cinchonains II a and II b from Cinchona succirubra. Chem Pharm Bull 1982; 30: 4277-4282

14 Hsu FL, Nonaka GI, Nishioka I. Tannins and related compounds. XXXI. Isolation and characterization of proanthocyanidins in Kandelia candel (L.) Druce. Chem Pharm Bull 1985; 33: 3142-3152

15 Chen HF, Tanaka T, Nonaka GI, Fujioka T, Mihashi K. Phenylpropanoidsubstituted catechins from Castanopsis hystrix and structure revision of cinchonains. Phytochemistry 1993; 33: 183-187

16 Ezaki-Furuichi E, Nonaka GI, Nishioka I, Hayashi K. Isolation and structures of procyanidins (condensed tannins) from Rhophiolepsis umbellata. Agric Biol Chem 1986; 50: 2061-2067

17 Ito H, Kobayashi E, Takamatsu Y, Li SH, Hatano T, Sakagami H, Kusama K, Satoh K, Sugita D, Shimura S, Itoh Y, Yoshida T. Polyphenols from Eriobotrya japonica and their cytotoxicity against human oral tumor cell lines. Chem Pharm Bull (Tokyo) 2000; 48: 687-693 
18 Qa'dan F, Verspohl EJ, Nahrstedt A, Petereit F, Matalka KZ. Cinchonain Ib isolated from Eriobotrya japonica induces insulin secretion in vitro and in vivo. J Ethnopharmacol 2009; 124: 224-227

19 Thien DG, Nguyen THA, Porzel A, Franke K, Wessjohann L, Sung TV. Triterpene acids and polyphenols from Eriobotrya poilanei. Biochem Syst Ecol 2012; 40: 198-200

20 Hokkanen J, Mattila S, Jaakola L, Pirttilä AM, Tolonen A. Identification of phenolic compounds from lingonberry (Vaccinium vitis-idaea $\mathrm{L}$.), bilberry (Vaccinium myrtillus L.) and hybrid bilberry (Vaccinium x intermedium Ruthe L.) leaves. J Agric Food Chem 2009; 57: 9437-9444

21 Friedrich W, Eberhardt A, Galensa R. Investigation of proanthocyanidins by HPLC with electrospray ionization mass spectrometry. Eur Food Res Technol 2000; 211: 56-64

22 Gu L, Kelm MA, Hammerstone JF, Zhang Z, Beecher G, Holden J, Haytowitz $D$, Prior RL. Liquid chromatographic/electrospray ionization mass spectrometric studies of proanthocyanidins in foods. J Mass Spectrom 2003; 38: 1272-1280

23 Salminen JP, Karonen M, Lempa K, Liimatainen J, Sinkkonen J, Lukkarinen $M$, Pihlaja K. Characterization of proanthocyanidin aglycones and glycosides from rose hips by high-performance liquid chromatography- mass spectrometry, and their rapid quantification together with vitamin C. J Chromatogr A 2005; 1077: 170-180

$24 \mathrm{Rohr}$ GE. Analytical Investigation on and Isolation of Procyanidins from Crataegus Leaves and Flowers [dissertation]. Zürich: Swiss Federal Institute of Technology; 1999

25 Liu P, Kallio H, Yang B. Characterisation of phenolic compounds in Chinese Hawthorn (Crataegus pinnatifida Bge. var. major) fruits by high performance liquid chromatography-electrospray ionization mass spectrometry. Food Chem 2010; 121: 1188-1197

26 Liu P, Kallio H, Lü D, Zhou C, Yang B. Quantitative analysis of phenolic compounds in Chinese Hawthorn (Crataegus ssp.) fruits by high performance liquid chromatography-electrospray ionisation mass spectrometry. Food Chem 2011; 127: 1370-1377

27 Porter LJ, Lai YF, Furneaux RH. Isolation of three naturally occurring O$\beta$-glucopyranosides of procyanidin polymers. Phytochemistry 1985; 24: 567-569

28 Raab T, Barron D, Vera FA, Crespy V, Oliveira M, Williamson G. Catechin glycosides: occurrence, synthesis, and stability. J Agric Food Chem 2010; 58: 2138-2149 